\title{
Functional Differentiation of Neural Stem Cells into Neuronal Subtypes: A Biological Tool for Developmental Neurotoxicity Studies
}

\author{
Ankita Pandey ${ }^{1}$ and Madhulika Singh ${ }^{2 *}$ \\ 'Developmental Toxicology Laboratory, System Toxicology and Health Risk Assessment Group, \\ CSIR-Indian Institute of Toxicology Research (CSIR-IITR), 31, Vishvigyan Bhawan, MG Marg, Lucknow - 226001, Uttar Pradesh, \\ India and Department of Zoology, Maharishi University of Information Technology Sitapur Road (IIM Bypass, Bhitauli Tiraha), \\ P. O. Maharishi Vidya Mandir, Lucknow - 226013, Uttar Pradesh, India; ankitaakasomu@gmail.com \\ 2Department of Zoology, Maharishi University of Information Technology Sitapur Road (IIM Bypass, Bhitauli Tiraha), \\ P. O. Maharishi Vidya Mandir, Lucknow - 226013, Uttar Pradesh, India; madhulika.anil@gmail.com
}

\begin{abstract}
Neural Stem Cells (NSCs), owing to their potential to get differentiated into various mature cell subtypes including neuronal cells have proved to be an indefinite source of 'raw material' for their application in developmental neurotoxicity as well as therapeutic intervention in neurodegenerative disorders. However, applications of NSCs for such purposes have been broadly limited by lack of enough methods for their directed differentiation. Herein, we describe a chemically defined protocol for efficient differentiation of rat neural stem cells to neuronal subtypes using an 8-day time period. NSCs, subject to NGF ( $50 \mathrm{ng} / \mathrm{mL})$ were differentiated into neuronal sub-types supplemented with a cocktail of growth factors and supplements. Differentiating cells revealed a gradual and significant induction in the neuronal markers and a parallel decrease in markers of stemness as confirmed by immunocytochemical and translational analysis. The expression of markers was found to be maximum at day 8 of differentiation. Such selective differentiation of NSCs into neurons could offer an imperative step towards generation of NSC derivatives that could facilitate their utilization for research studies.
\end{abstract}

Keywords: Nerve Growth Factor, Neural Stem Cells, Neuronal Subtypes

\section{Introduction}

Therapeutic application of NSC differentiation into neurons for tissue transplantation studies has been a significant hallmark of stem cell research. With capabilities of differentiating into neurons, oligodendrocytes and astrocytes, NSCs, serve as a promising tool for the treatment of many acquired and hereditary diseases of $\mathrm{CNS}^{1}$. More recently, their application has also been extended to elucidate the toxic effects of a variety of environmental contaminants. In addition, the efficient differentiation of NSCs has also raised the possibility that it may provide a novel source of neuronal cells for nervous tissue replacement or repair after injury or neurodegeneration 2 .
Neurogenesis is a multistep developmental process of producing functionally active neurons from their precursors 3 . For a long time, it was believed that no new neurons were generated in the adult Central Nervous System (CNS). The concept of neurogenesis gained momentum with the identification of cell division in the adult brain of birds and rodents 4.5. . In 1992 NSCs were isolated from the striatum of adult mice and grown in the presence of Epidermal Growth Factor (EGF). Post EGF removal, cells could differentiate and express markers of neural or glial origin, an indication of stem cells in the adult brain ${ }^{6}$.) These findings gave birth to a very useful in vitro model to understand cell fate determination.

Extensive therapeutic potential exhibited by NSCs has fuelled various attempts to develop and apply protocols to

*Author for correspondence 
direct their differentiated fate towards particular lineage for their utilization in various studies. To recapitulate the differentiation process of NSCs in in-vitro has been a Herculian task. Studies revealed, that apart from internal features of stem cells, their external environment, including presence of growth factors, cytokines as well as cell-cell contacts, have played a crucial function in influencing the ultimate fate of these cells. Basic Fibroblast Growth Factor (BFGF) and Epidermal Growth Factor (EGF) have revealed to influence the proliferation and differentiation of NSCs in-vitro ${ }^{7}$. Neurotrophic factors like Neurotrophin-3 (NT-3) and Brain-derived Neurotrophic Factor (BDNF), in addition, are also crucial role players influencing the subtype of NSCs ${ }^{8}$. Apart from these cell to cell contact signals may also control the differentiation process. For example, co-culturing of ammonic cells and astrocytes led to enhancement of NSC differentiation into neurons? Electrical stimulation using carbon nanotube ropes might also trigger the differentiation process ${ }^{10}$. However, these various strategies of NSCs differentiation have few limitations such as chemical toxicity, insufficient cell-specific differentiation and several others ${ }^{\underline{11}}$. Therefore, there has been a pressing need for better and more efficient protocols for differentiation of NSCs.

The mammalian brain is enriched with various neurotrophins/growth factors essential for the process of neurogenesis. Nerve Growth Factor (NGF) is the main growth factor known to be involved in the cellular functions such as protection from cellular injury and enhancement of cell repairing process ${ }^{\underline{12}}$. Since neurogenesis is majorly supported by the neurotrophins in brain, therefore, in the current study, we have attempted to explore the neurogenesis potential of NGF to trigger induction of neuronal differentiation in NSCs.

This study was thus undertaken to develop and standardize a protocol for efficient isolation, characterization, proliferation and subsequent differentiation of NSCs towards neuronal lineage with a high selectivity. The undifferentiated as well as differentiated cell fate was identified by western blot assay analysis and immunofluorescence microscopy. Along with morphological studies, expressional analysis of various cellspecific biomarkers such as nestin (a type-IV intermediate filament: marker for neural progenitor cells), BrdU (proliferation marker), $\beta$-III-tubulin (component of the microtubular complex: marker for mature neurons) and ChAT (marker of cholinergic neurons) were employed to determine the different cell lineages.

\section{Materials and Method}

\subsection{Reagents and Consumables}

All the reagents, chemicals and kits employed in the study were procured from Sigma, unless otherwise stated. Neurobasal Medium, Fetal Bovine Serum, GlutaMAX ${ }^{\mathrm{TM}}-\mathrm{I}$ (100X), Penicillin- Streptomycin antibiotic solution (100X), Sodium bicarbonate (7.5\%), Phosphate Buffered saline were procured from Gibco (Invitrogen, USA) and antibodies from Millipore (USA).

\subsection{Isolation of NSCs}

NSCs were extracted from embryonic day-16 rat foetus. The isolated tissue was then washed and dissected with chilled HBSS (Hanks Balanced Salt Solution), incubated for $30 \mathrm{~min}$ in $0.1 \%$ trypsin, then in DNase $(40 \mu \mathrm{g} / \mathrm{ml})$ for $10 \mathrm{~min}, 37^{\circ} \mathrm{C}$ to get a single cell homogenous suspension. Cells that showed more than $95 \%$ viability were seeded at a density of $0.5 \times 10^{6}$ cells $/ \mathrm{ml}$ in $75 \mathrm{~cm}^{2}$ flasks in neurobasal medium and were allowed to proliferate as neurospheres in $5 \% \mathrm{CO}_{2}$ and $95 \%$ air at $37^{\circ} \mathrm{C}$.

\subsection{Proliferation and Characterization of NSCs}

Expansion of proliferating NSCs was carried out in neurobasal medium with supplements N-2 (1\%), B-27 (2\%), EGF (10 ng/ $\mathrm{ml})$ and bFGF (10 ng/ml). Small neurospheres were observed post 1 week that matured by day 20. Passaging was carried out after every 10-12 days. To visualize the proliferating activity of NSCs and to identify the undifferentiated progenitor cells, neurospheres were co-immunostained with anti-nestin monoclonal antibody (1:200; a neural stem cell marker) and anti-BrdU antibody (1:500, proliferating cells marker).

\subsection{NGF induced neuronal differentiation of NSCs}

NSCs were seeded on pre-PLL coated $25 \mathrm{~cm}^{2}$ flask $\left(1 \mathrm{X} 10^{6}\right.$ per flask) and subsequently cultured for $24 \mathrm{~h}$. The cells were further incubated in neurobasal medium (deprived of growth factors and supplements) for $24 \mathrm{~h}$ prior to exposure to NGF. For induction of differentiation into cholinergic neurons, cells were incubated in medium containing NGF $(50 \mathrm{ng} / \mathrm{ml})$ along with lowered concentrations of EGF and bFGF $(1 \mathrm{ng} / \mathrm{mL})$, B-27 (0.1\%) and N-2 (1\%). Concentration of NGF (50 ng/ml) 
was selected based on previous studies reporting optimal differentiation using different cell cultures ${ }^{\underline{13}}$. Exposure was given till 8 days and exposure medium was removed and replenished every alternate day. The differentiated cells were characterized for expression of mature neuronal markers using western blotting and immunocytochemical analysis.

\subsection{Immunocytochemical Localization}

Immunocytochemical studies were carried out employing the protocol briefly described $\underline{14}$. Post different exposures, the medium was replaced with $4 \%$ paraformaldehyde for 20 min for fixation. Further cells were gently washed with $1 \mathrm{X}$ PBS two times and then non-specific sites were blocked with $0.02 \%$ Triton X 100 and $0.1 \%$ BSA in PBS for 1 h at room temperature. Post blocking cells were incubated with primary antibodies against specific proteins, viz. Nestin (1:250), BrdU (1:500), ChAT (1:250) and $\beta$-III tubulin $(1: 150)$ at $4^{\circ} \mathrm{C}$ overnight. Next, unbound primary antibodies were removed by gently washing cells with 1X PBS. Next, Alexa Fluor secondary antibodies (1:150) were added and the cells were incubated in dark at room temperature for $1 \mathrm{~h}$. Next, unbound secondary antibodies were removed by gently washing cells with $1 \mathrm{X}$ PBS. Next, the cells were observed under Nikon Eclipse 80i using particular filters and captured which were analyzed for their fluorescent intensity by Leica Qwin 500 Image Analysis Software (Leica, Germany).

\subsection{Translational Study}

Western blotting was carried out employing the protocol briefly described 15 . Of the total protein, 30-40 $\mu \mathrm{g}$ was electrophoresed in a 10\%-12\% SDS-PAGE and transferred onto
PVDF membrane using transfer buffer (25mM Tris [pH 8.3], $190 \mathrm{mM}$ glycine, and $20 \%$ methanol) for $2 \mathrm{~h}$ with a current of $250 \mathrm{~mA}$. Nonspecific sites were blocked with 5\% BSA in TBST (20mM Tris- $\mathrm{HCl}$ [pH 7.4], 137mM NaCl, and 0.1\% Tween 20) for $2 \mathrm{~h}$ at $37^{\circ} \mathrm{C}$. Post blocking the membrane was incubated with primary antibodies (Nestin (1:1000), ChAT (1:1000) and $\beta$-III tubulin (1: 1000) and $\beta$-actin (1:2000)) against specific proteins at $4^{\circ} \mathrm{C}$ overnight. After washing with $1 \mathrm{X}$ TBST thrice for $10 \mathrm{~min}$ the membrane was next incubated with secondary antibodies (conjugated with HRP, Chemicon, 1:2000) at room temperature for $2 \mathrm{~h}$. Post washing with 1X TBST, expression levels for different proteins were developed using chemiluminescent Substrate (Thermo Fisher Scientific) and Bio-Rad Versa Doc Imaging System 4000 (Bio-Rad, Philadelphia, PA).

\subsection{Statistical Analysis}

Results have been expressed as mean \pm Standard Error of Mean (SEM) from the values that were obtained from at least three independent experiments. Statistical analysis was computed using one-way analysis of variance (ANOVA) and Dunnett's Multiple Comparison test employing Graph Pad prism (Version 5.0) software.

\section{Results}

\subsection{Isolation, Characterization and Proliferation of NSCs}

Rat brain NSCs were successfully isolated from embryonic day-16 rat foetus (Figure 1a). The proliferating cells grown in neurobasal medium could be seen as small neurospheres by

\section{Day 0}

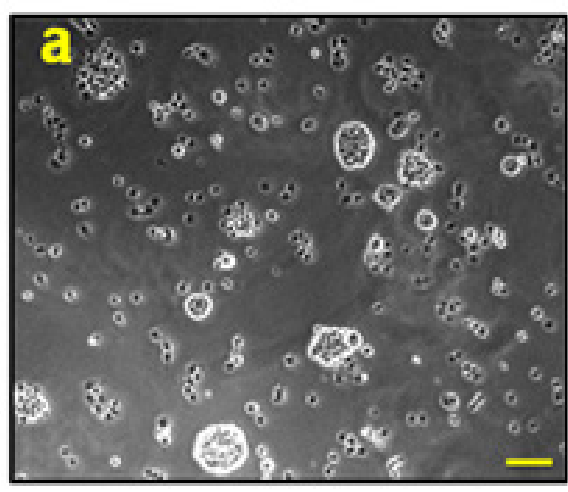

Day 7

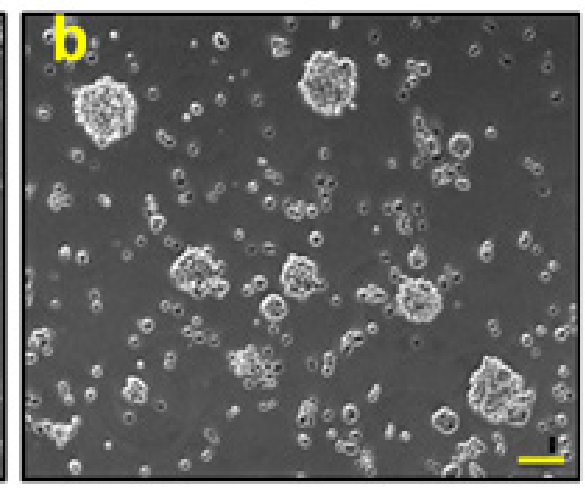

Day 20

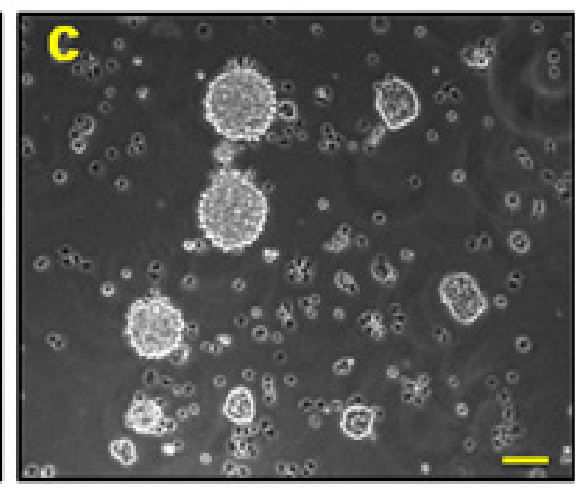

Figure 1. Figure 1: (a) Rat brain NSCs isolated from embryonic day-16 rat foetus (b) Proliferating cells observed as small neurospheres by day 7 (c) The neurospheres gained maturity by day 20. 

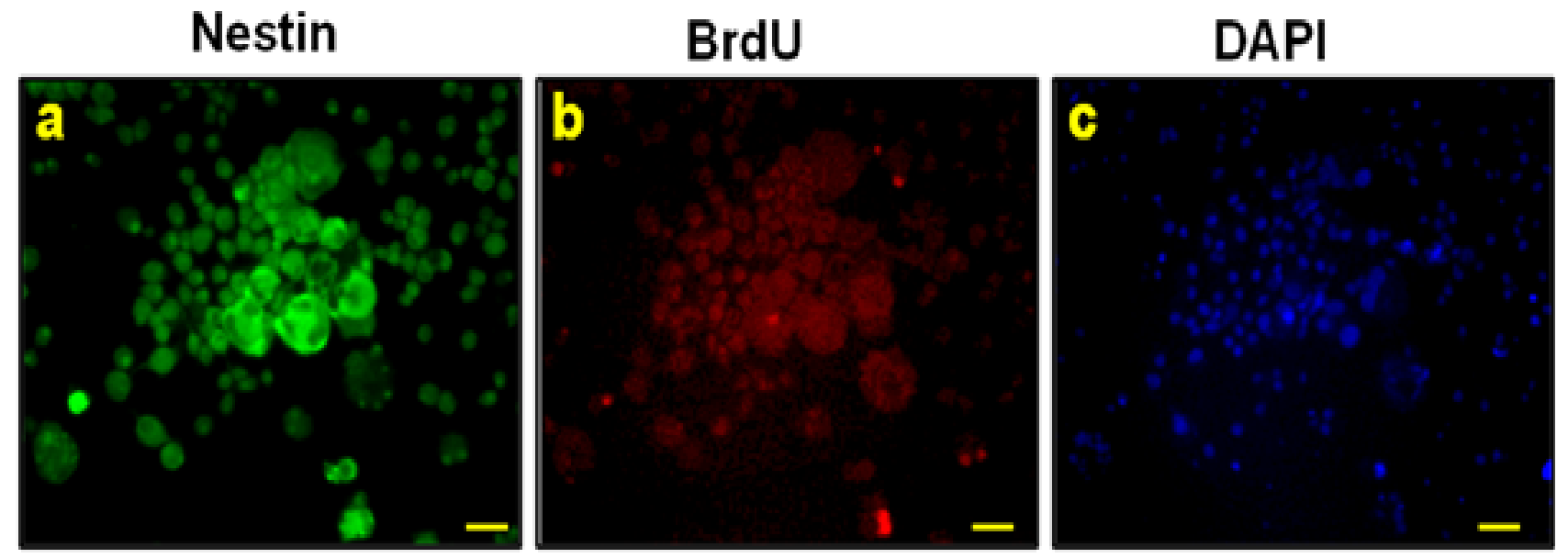

Figure 2. NSCs showing immunoreactivity for both (a) nestin (green) and (b) BrdU (red) (c) counterstained.

day 7 (Figure 1b) that gained maturity and grew significantly both in size and number by day 20 (Figure 1c). Cells in the neurospheres expressed both progenitor cell marker-nestin (green) as well as proliferative cell marker-BrdU (red) indicative of their stemness nature (Figure $2 \mathrm{a}-\mathrm{c}$ ).

\subsection{Morphological Analysis of Neuronal Differentiation Induced by NGF}

We next analysed NSCs for their potential to undergo neural differentiation under the influence of $50 \mathrm{ng} / \mathrm{ml}$ of NGF. On day 2, we observed few morphological alterations such as cells becoming longer as compared to Day 0. By day 4 and 6, cells revealed neurite like extensions that became more prominent by day 8 (Figure 3a-d). Quantitative analysis revealed that
NGF had the potential to induce significant neurite outgrowth in a time dependent manner. (Figure 4A (a-e) and Figure 4B).

\subsection{Expressional Analysis of Neuronal Differentiation Induced by NGF}

To further confirm the neurotrophic effect of NGF, protein expression of $\beta$-III-tubulin and ChAT was determined over an 8-day period via immunocytochemical localization (Figure 4A and $4 \mathrm{C}$ ). Western blot analysis (Figure $5 \mathrm{~A}$ and $5 \mathrm{~B}$ ) revealed time dependent significant increase in expression of $\beta$-IIItubulin and ChAT as compared to the day 0 . Simultaneously there was a decrease in expression of the stemness marker nestin, indicative of differentiation of neural stem cells towards neuronal lineage.
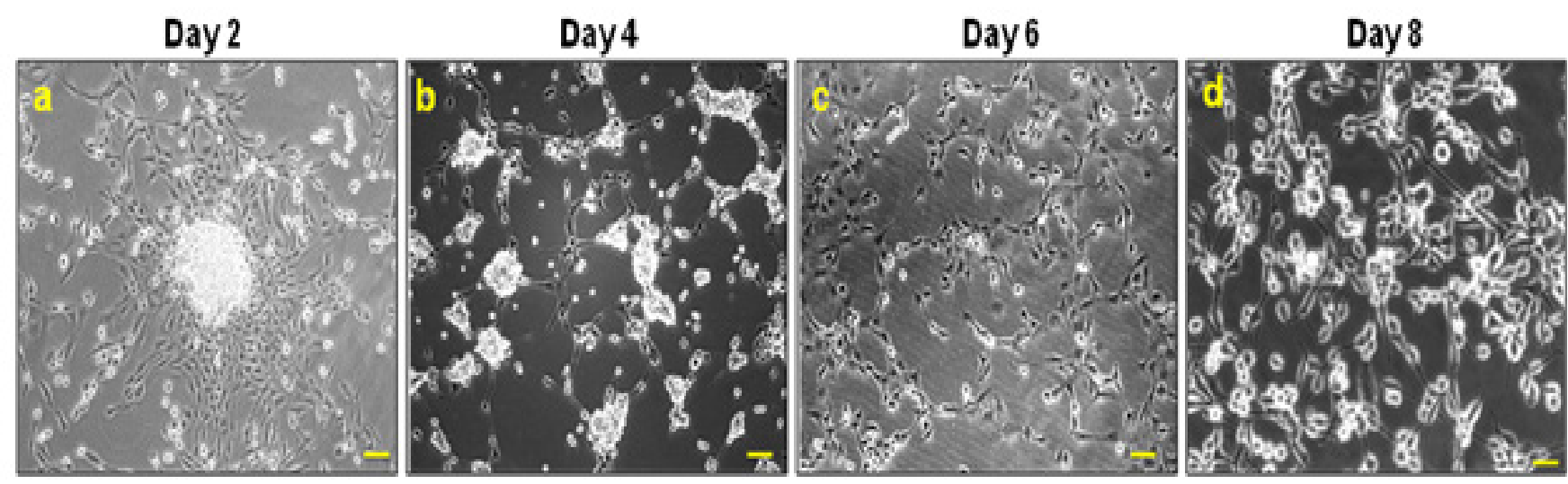

Figure 3. (a-d) Representative microphotographs revealing alterations in morphology on neuronal induction by NGF (50ng/ml). 
Figure 4 A

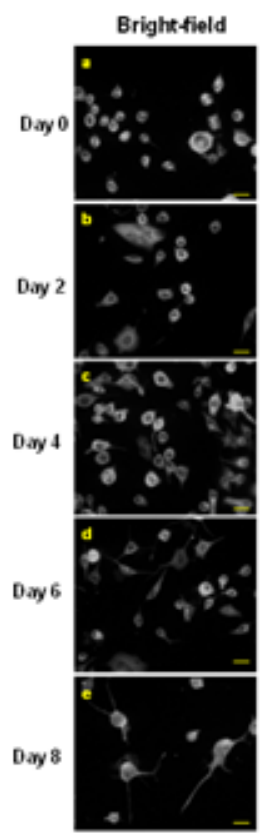

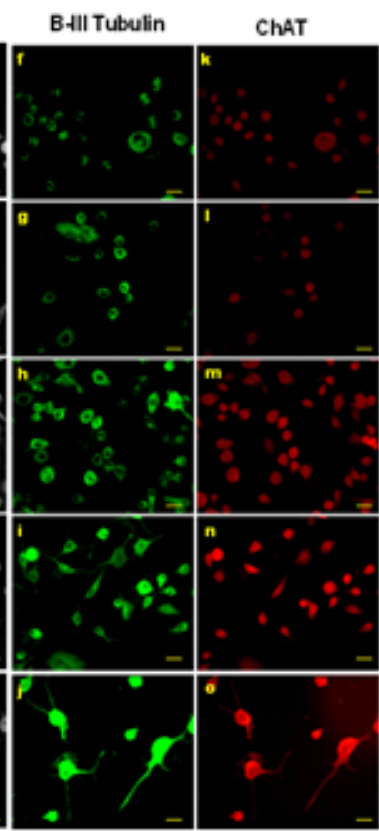

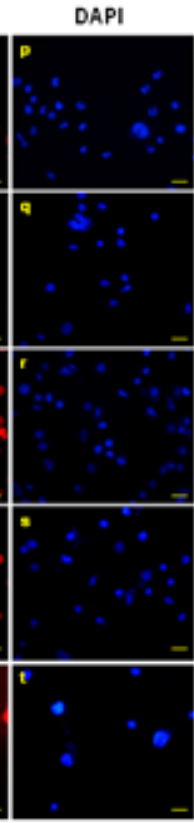

Figure 4 B

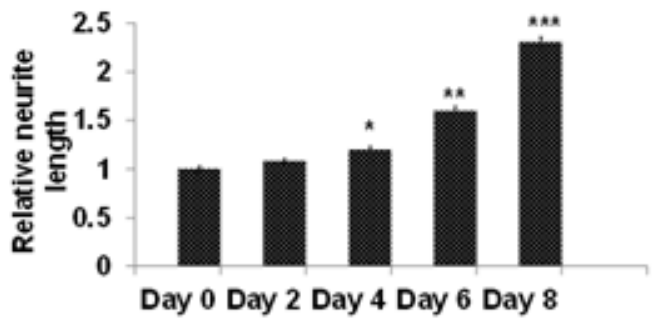

Figure 4 C

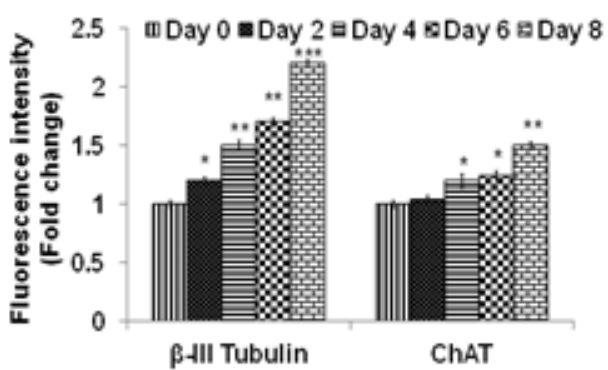

Figure 4. A. (a-e) and B Morphological and quantitative analysis of relative neurite length. (A (f-t)) Differentiated NSCs showed neuronal morphology and stained positive for neural marker $\beta$-III tubulin (green) and cholinergic specific marker ChAT (red) counter stained with DAPI. (C) Relative fluorescence intensities expressed in fold change. ${ }^{\star}=\mathrm{p}<0.05,{ }^{*}=\mathrm{p}<0.01,{ }^{*}{ }^{*}=\mathrm{p}<0.001$.

Figure $5 \mathrm{~A}$

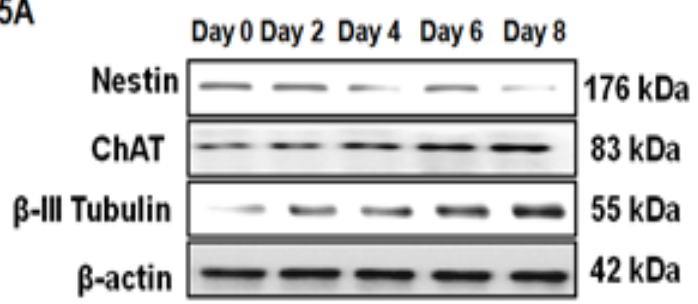

Figure 5B

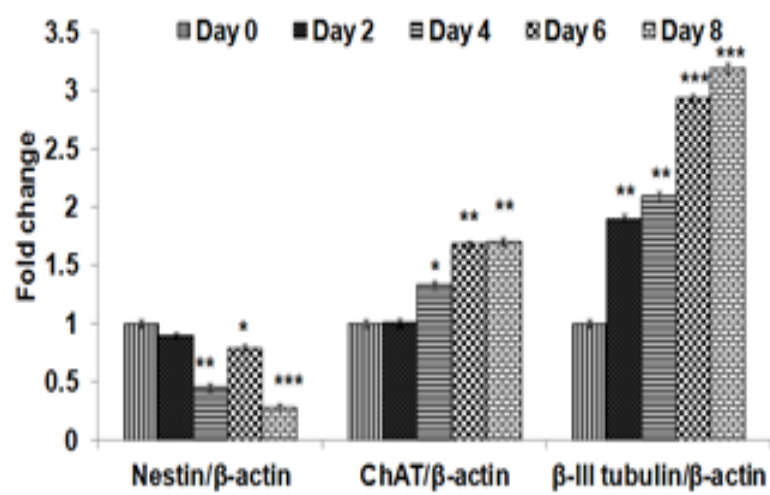

Figure 5. Expressional analysis of markers of stemness (Nestin) and neuronal markers ( $\beta$-III tubulin and ChAT) under NGF exposure over an 8-day time period. ${ }^{*}=\mathrm{p}<0.05,{ }^{*}=\mathrm{p}<0.01,{ }^{*}$ $\star *=\mathrm{p}<0.001$.

\section{Discussion}

NSCs have been one of the potential candidates for restoration of central nervous system injury, such as neurodegenerative diseases, stroke and traumatic brain injury ${ }^{16}$. More recently, their application for developmental neurotoxicity studies has received much attention in identification of stage specific markers activated in response to a range of toxicants that have shed light on the underlying toxicity mechanisms ${ }^{17}$.

The main objective of culturing NSCs in vitro has been to regulate the proliferation and ultimate differentiation into different cell types. Unfortunately, such efforts have been met with only limited success. A plethora of studies have revealed that exposure to NT-3, BDNF and Shh, sequentially, significantly enhanced the neuronal differentiation from NSCs both in vitro or in vivo after transplantation $\stackrel{8}{*}$. Moreover cytokines, chemicals, electrical stimulation have all shown to affect the differentiation process. These results were suggestive of the fact that the external environment has a significant involvement in triggering NSCs to differentiate into neurons $s^{18}$.

NGF is a major biologically active molecule that is actively involved neurogenesis. As a neurotransmitter, NGF has been 
convincingly demonstrated to control proliferation and differentiation of $\mathrm{NSCs}^{19}$ and has been earlier used to induce many cells such as PC12, SH-SY5Y into mature neurons under in vitro conditions ${ }^{20.21}$. More recently, exogenous NGF supplementation on Human Derived Mesenchymal Stem Cells (hMSCs) was also studied $\frac{13}{3}$. Among the different concentrations of NGF that were tested, NGF at $50 \mathrm{ng} / \mathrm{mL}$ concentration could most significantly trigger differentiation of hMSCs into neuronal lineage.

In an attempt to find new approaches, we have standardized a protocol to isolate, characterize and differentiate neural stem cells to neuronal lineages that have been confirmed through a panel of characterization techniques. Specific markers were selected to characterize particular cell lineages. Nestin, an intermediate filament protein commonly used to label undifferentiated NSCs was found to be down-regulated over the 8 -day time period. $\beta$-Tubulin III, a cytoskeletal protein whose expression elevates during axonal outgrowth, is expressed by mature neurons (Lee et al., 1990) and ChAT, a cholinergic marker, both simultaneously significantly elevated. Stage specific increase in expression of neuronal markers indicated the effective differentiation over an 8-day time period. These experiments support our conclusion that was NGF is an important factor in determining stem cell differentiation. These stage specific alterations could be used to study the effects of toxicants by monitoring changes in expressional levels.

In this study, it was thus identified that exogenous supplementation of NGF could direct the differentiation of NSCs towards the neuronal subtypes. As indicated by immunocytochemical staining and Western blotting examination, it was observed that NGF had the potential to promote the growth of processes and distinct differentiation of NSCs into neurons from embryonic rat brain cultured neural stem cells. Furthermore, the mechanism and signaling pathway of neuronal differentiation of NSCs in NGF supplementation conditions are still to be further investigated.

\section{Acknowledgement}

The authors thank Dr AB Pant, Principal Scientist, Developmental Toxicology Division, CSIR-Indian Institute of Toxicology Research, Lucknow for taking keen interest and providing the state of the art facilities to conduct this research work.

\section{References}

1. Aboody K, Capela A, Niazi N, Stern JH, Temple S. Translating stem cell studies to the clinic for CNS repair: current state of the art and the need for a Rosetta stone. Neuron. 2011; 70(4):597-613. https://doi.org/10.1016/j.neuron.2011.05.007. PMid:21609819.

2. Rossi F, Cattaneo E. Opinion: neural stem cell therapy for neurological diseases: dreams and reality. Nature Reviews Neuroscience. 2002; 3(5): 401-409. https://doi.org/10.1038/ nrn809. PMid:11988779.

3. Kempermann G, Jessberger S, Steiner B, Kronenberg G. Milestones of neuronal development in the adult hippocampus. Trends in Neurosciences. 2004; 27(8): 447-52. https://doi. org/10.1016/j.tins.2004.05.013. PMid:15271491.

4. Ming G-l, Song H. Adult neurogenesis in the mammalian brain: significant answers and significant questions. Neuron. 2011; 70(4): 687-702. https://doi.org/10.1016/j.neuron.2011.05.001. PMid:21609825 PMCid:PMC3106107.

5. Gage FH. Mammalian neural stem cells. Science. 2000; 287 (5457): 1433-38. https://doi.org/10.1126/science.287.5457.1433. PMid:10688783.

6. Reynolds BA, Weiss S. Generation of neurons and astrocytes from isolated cells of the adult mammalian central nervous system. Science. 1992; 255(5052): 1707-10. https://doi.org/10.1126/ science. 1553558.

7. Konagaya S, Kato K, Nakaji-Hirabayashi T, Arima Y, Iwata H. Array-based functional screening of growth factors toward optimizing neural stem cell microenvironments. Biomaterials. 2011; 32(22): 5015-22. https://doi.org/10.1016/j. biomaterials.2011.03.066. PMid:21513976.

8. Moyse E, Segura S, Liard O, Mahaut S, Mechawar N. Microenvironmental determinants of adult neural stem cell proliferation and lineage commitment in the healthy and injured central nervous system. Current Stem Cell Research \& Therapy. 2008; 3(3): 163-184. https://doi. org/10.2174/157488808785740334.

9. Wang F-w, Hao H-b, Zhao S-d, Zhang Y-m, Liu Q, Liu H-j, et al. Roles of activated astrocyte in neural stem cell proliferation and differentiation. Stem Cell Research. 2011; 7(1): 41-53. https:// doi.org/10.1016/j.scr.2011.03.004. PMid:21530437.

10. Huang YJ, Wu HC, Tai NH, Wang TW. Carbon nanotube rope with electrical stimulation promotes the differentiation and maturity of neural stem cells. Small. 2012; 8(18): 2869-77. https://doi. org/10.1002/smll.201200715. PMid:22753249.

11. Rossi F, Cattaneo E. Opinion: neural stem cell therapy for neurological diseases: dreams and reality. Nature Reviews Neuroscience. 2002; 3(5): 401-409. https://doi.org/10.1038/ nrn809. PMid:11988779.

12. Blesch A, Lu P, Tuszynski MH. Neurotrophic factors, gene therapy, and neural stem cells for spinal cord repair. Brain Research Bulletin. 2002; 57(6): 833-38. https://doi.org/10.1016/S03619230(01)00774-2.

13. Jahan S, Kumar D, Kumar A, Rajpurohit CS, Singh S, Srivastava A, et al. Neurotrophic factor mediated neuronal differentiation of human cord blood mesenchymal stem cells and their applicability 
to assess the developmental neurotoxicity. Biochemical and Biophysical Research Communications. 2017; 482(4): 961-67. https://doi.org/10.1016/j.bbrc.2016.11.140. PMid:27899317.

14. Kumar V, Pandey A, Jahan S, Shukla RK, Kumar D, Srivastava A, et al. Differential responses of Trans-Resveratrol on proliferation of neural progenitor cells and aged rat hippocampal neurogenesis. Scientific Reports. 2016; 6: 28142. https://doi.org/10.1038/ srep28142. PMid:27334554. PMCid:PMC4917886.

15. Kumar V, Gupta AK, Shukla RK, Tripathi VK, Jahan S, Pandey A, et al. Molecular Mechanism of Switching of TrkA/p75NTR Signaling in Monocrotophos Induced Neurotoxicity. Scientific Reports. 2015; 5: 14038. https://doi.org/10.1038/srep14038. PMid:26370177. PMCid:PMC4570211.

16. Orlacchio A, Bernardi G, Martino S. Stem cells: an overview of the current status of therapies for central and peripheral nervous system diseases. Current Medicinal Chemistry. 2010; 17(7): 595-608. https://doi.org/10.2174/092986710790416272. PMid:20088765.

17. Singh S, Srivastava A, Kumar V, Pandey A, Kumar D, Rajpurohit C, et al. Stem cells in neurotoxicology/developmental neurotoxicology: current scenario and future prospects.
Molecular Neurobiology. 2016; 53(10): 6938-49. https://doi. org/10.1007/s12035-015-9615-2. PMid:26666665.

18. Tarasenko YI, Yu Y, Jordan PM, Bottenstein J, Wu P. Effect of growth factors on proliferation and phenotypic differentiation of human fetal neural stem cells. Journal of Neuroscience Research. 2004; 78(5): 625-36. https://doi.org/10.1002/jnr.20316. PMid:15490463.

19. Faigle R, Song H. Signaling mechanisms regulating adult neural stem cells and neurogenesis. Biochimica et Biophysica Acta (BBA)-General Subjects. 2013; 1830(2): 2435-48. https://doi.org/10.1016/j.bbagen.2012.09.002. PMid:22982587. PMCid:PMC3541438.

20. Hagag N, Halegoua S, Viola M. Inhibition of growth factorinduced differentiation of PC12 cells by microinjection of antibody to ras p21. Nature. 1986; 319(6055): 680-82. https://doi. org/10.1038/319680a0. PMid:3005866.

21. Gomez-Santos C, Ferrer I, Santidrian AF, Barrachina M, Gil J, Ambrosio S. Dopamine induces autophagic cell death and $a-$ synuclein increase in human neuroblastoma SH-SY5Y cells. Journal of Neuroscience Research. 2003; 73(3): 341-50. https:// doi.org/10.1002/jnr.10663. PMid:12868068. 